\title{
Fine needle aspiration biopsy "FNAB" for peripheral lung lesions: diagnostic value, complications and role of US guidance.
}

\author{
Aasem M. AL-Chalabi * Hazim K. AL-Allaf ** Talal AL-Saegh*** \\ *Ninevah Private hospital, Mosul; **Department of Radiology, College of Medicine, Mosul University; \\ ***lbn- Sina teaching hospital, Mosul.
}

(Ann. Coll. Med. Mosul 2007; 33(1\&2):9 - 14)

Received: $4^{\text {th }}$ Jun 2007; Accepted: $14^{\text {th }}$ Nov 2007

\begin{abstract}
:
Objective: To assess the role of ultrasound in guiding fine needle aspiration lung biopsy in peripheral lung lesions.

Methods: Using real-time ultrasonography, Seimense Sonoline equipment with 3.5 and 5.0 $\mathrm{MHz}$ transducer, the patients were examined to localize the lesions and prepare for performing biopsy.

Main result: One hundred fifty patients having peripheral lung lesions, 119 (79.3\%) males and $31(20.7 \%)$ females with mean age of (56) years were exposed to lung biopsy. One hundred forty (140) patients showed malignant lesions. Six patients had tuberculosis, two patients had interstitial pneumonitis and other two were normal.

Conclusion: Ultrasound guided transthoracic biopsy appears very safe and effective method for the diagnosis of peripheral lung lesions when bronchoscopy failed to reach the lesion, and to avoid the need of thoracotomy to achieve that.
\end{abstract}

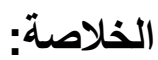

الهُف: دراسة أهمية فحص الموجات فوق الصوتية في الإرشاد والتوجيه لأخذ خزعة من الرئة في حالات الإصـابة بالعلل الطرفية الموقع.

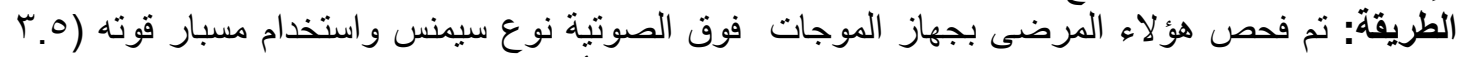

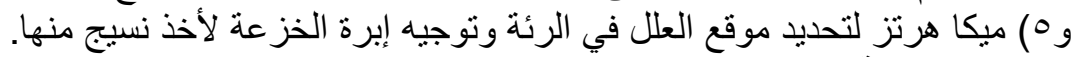

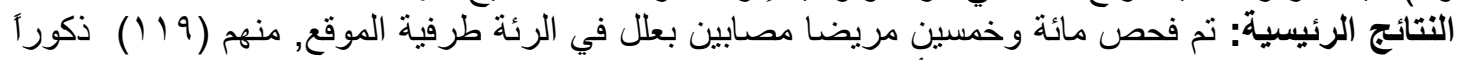

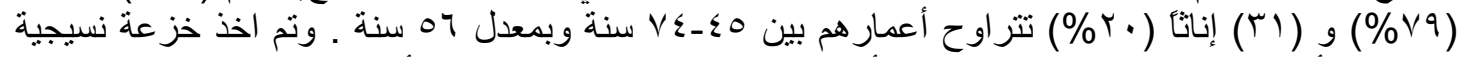

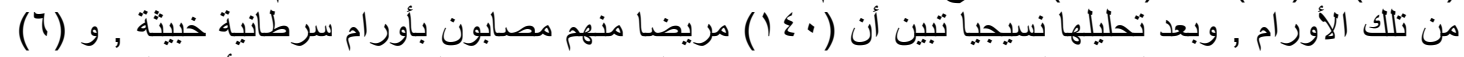

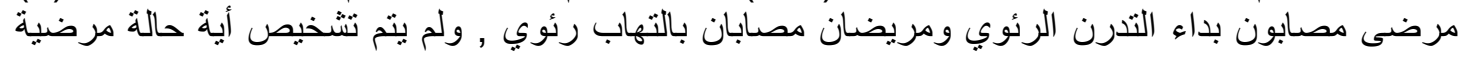

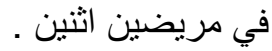

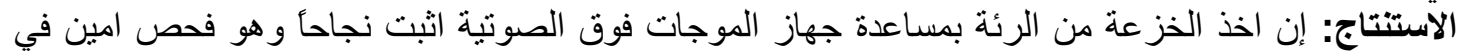

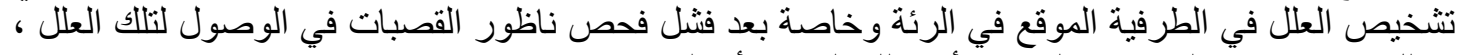
ويقلل من إجر اء عمليات فتح الصدر لأخذ تللك العينات أو الخزعات. 
$\mathrm{T}$ he investigation of peripheral pulmonary lesions detected by chest radiography begins by sputum examination and bronchoscopy. If these investigations prove non-diagnostic, percutaneous transthoracic needle biopsy of these lesions is indicated.

The use of percutaneous needle biopsy for diagnosis of intrathoracic lesions is not new. Since the advent of good image intensification and cytopathological techniques, this procedure has been practiced throughout the western world and several large series have been reported over the last three decades. ${ }^{(1-6)}$ Not withstanding, it remains underutilized and there is still some reluctance by clinicians and radiologists to accept this technique as one, which assists in the practical management of patients ${ }^{(7,8)}$. This is very true in our country and Middle East area.

In the United States, imaging-guided percutaneous transthoracic biopsy is generally performed under fluoroscopic or computed tomographic "CT" guidance ${ }^{(9-11)}$. Fluoroscopy fails when the lesions are small or near the mediastinum, or at the diaphragmatic, or apical lung surface, plus its radiation hazards. While CT scan can help in some of these situations ${ }^{(11)}$, its main limitations are the radiation exposure, the expense and unavailability in many centers. In addition, it can not provide a real image for the biopsy needle tip ${ }^{(12)}$. Ultrasound equipment is readily available in almost all centers.

The purpose of the present study was to determine the diagnostic value and complications of fine needle aspiration biopsy (FNAB) and to evaluate the role of ultrasound (US) guidance.

\section{Patients and methods:}

From January 2001 to January 2006, one hundred and fifty patients underwent percutaneous transthoracic needle biopsy. The procedure was requested by various general and subspeciality physicians because of peripheral lung shadow and negative flexible bronchoscopy. In all patients, sputum cytology, bacteriology, and fiberoptic bronchoscopy failed to make histological diagnosis.

There were 119 male $(79 \%)$ and 31 female patients $(21 \%)$ aged $45-74$ years "mean 56 years". All patients had chest X-ray postero-anterior and lateral view with lesion size ranging between $3-10 \mathrm{~cm}$; all were intrapulmonary. At the time of examination, all patients had normal coagulation parameters including platelets count, prothrombin and clotting time. Patients with bleeding diathesis, central or mediastinal lesions and sonographic and/or serological evidence of hydatid cysts, were excluded from FNAB.

Real-time ultrasonography was performed with Seimense Sonoline ultrasound machine using 3.5 and $5.0 \mathrm{MHz}$ transducers. In each patient, multiple scans were obtained using different body positions "supine, prone, sitting and lateral" until the most satisfactory scan was obtained. The liver and gallbladder were used as reference echopattern and lesions were characterized as hypoechoic, isoechoic and hyperechoic lesions.

A fine needle aspiration biopsy was performed using a 22-gauge steel needle attached to $20 \mathrm{ml}$ syringe. The ultrasound transducer is held parallel to the rib spaces to ensure maximum contact with chest wall and allow easy passage of the needle through the rib space.

After obtaining the most optimal view of the lesion, the fine needle was inserted during suspended mid-inspiration. The needle tip, seen as a white spot on monitor screen, was advanced until it reached the lesion. The needle was flushed with few drops of normal saline and pushed into the lesion while maintaining continuous suction by the syringe. Each fine-needle aspirate was immediately smeared onto glass slides, air dried, and stained with a modified WrightGiemsa, for acid fast. Slides were sent for histopathological examination. The needle then was flushed with normal saline and sent for culture. After the procedure is over, the patient is kept in the ward for 4-6 hours and inspiratory and expiratory chest X-ray films were obtained to rule out the development of pneumothorax. The average duration of the procedure was 15 minutes and all the patients had a satisfactory material from the first aspiration attempts. The final diagnosis was confirmed by either lymph node biopsy or clinical follow up.

\section{Results:}

Among the 150 patients examined, there were 119 males $(79 \%)$ and 31 females $(21 \%)$. Male:female ratio $3.8: 1$, with a mean age of 56 years (range from 45-74 
years) Fig. (1). Most of the lesions were on the right side $(66 \%)$ and $34 \%$ on the left side distributed as follows, $30 \%$ on the upper zone, $44 \%$ on the middle zone and $26 \%$ on the lower zone (Fig.2). The transverse diameter of the lesion measured on the chest X-ray varies from 3-10 $\mathrm{cm}$ with a mean of $4.4 \mathrm{~cm}$ (Figs.3,4). Associated lesions seen on chest X-ray were pleural effusion $6 \%$, collapse, secondary pneumonia, fibrosis and cavitating lesions were seen in $10 \%$ each.

Aspiration was successful in 150 (100\%) patients. Ultrasound-guided FNAB was diagnostic in 148 (98.6\%) and revealed normal cellularity in two patients. Table (I) showed the final diagnosis in 150 lesions. 140 lesions (93\%) were malignant confidently diagnosed by cytopathologist. The majority of malignant lesions (66\%) appeared as hypoechoic on sonographic examination. Of the remaining 8 patients, 6 were proved to have tuberculosis, 2 were diagnosed with interstitial pneumonitis. The two patients where aspirate showed normal lung cells had isoechoic sonographic appearance, and these two patients showed no change in the lesion on one month follow up chest $X$ ray. The other two patients with pneumonic consolidation showed complete disappearance of the lesion on chest X-ray follow up. Table (2) showed the cytopathological diagnosis in 140 patients with malignant lesions.

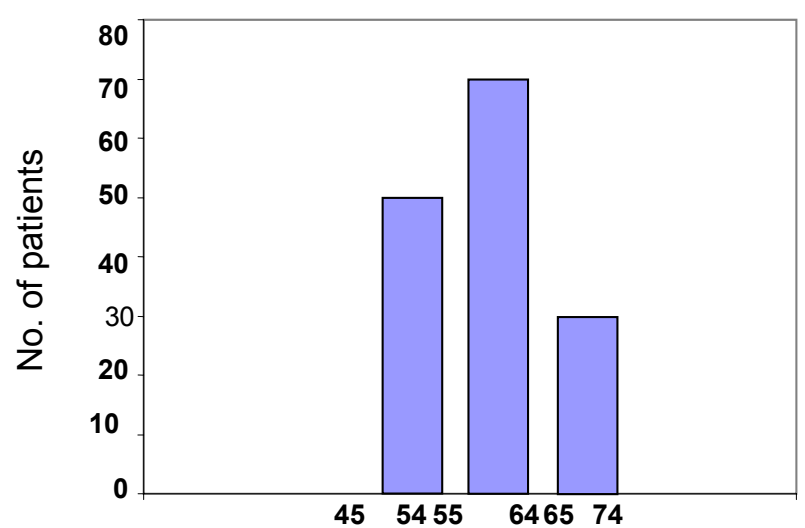

Age in years

Fig.(1): Histogram show the age distribution of the patients.
Of the 150 patients who underwent ultrasound guided FNAB, none developed any procedure related complications.

Follow up of the patients after FNAB and histopathologic result were done to verify the diagnostic yield of this procedure. Ninety eight of the 140 patients with malignant lesions were followed at the radiotherapy department. All of them received radiotherapy and their lesion responded to this treatment. Some of these patients $(20 \%)$ developed peripheral cervical lymph node enlargement and biopsy of these nodes confirmed the presence of the same malignant lesion in the lymph nodes as that detected by FNAB confirming its validity. The 6 patients with tuberculosis were given specific anti-tuberculous treatment and the lesion subsided confirming the histological diagnosis gained by FNAB. One patient had thoracotomy which proved the diagnosis of FNAB of neurofibrosarcoma. Ultrasound guided fine needle aspirate biopsy procedure which was done in all these 150 patients proved to be totally successful which gave an accuracy of $100 \%$.

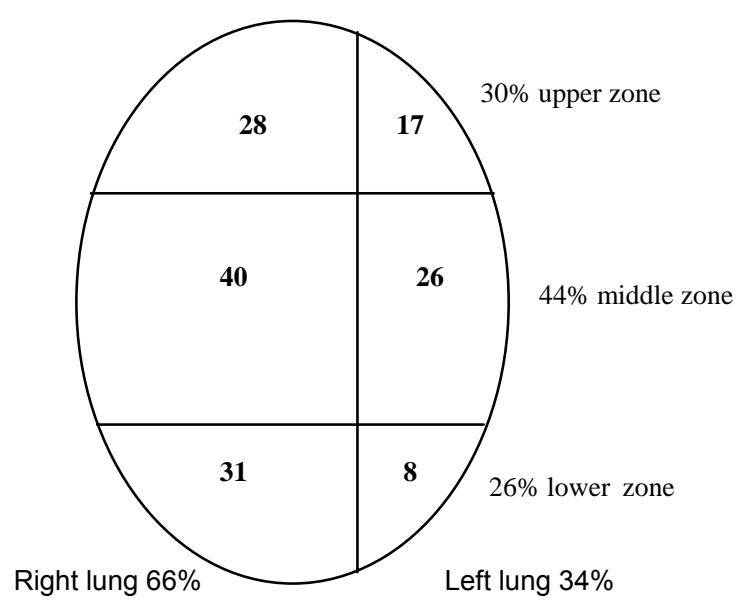

Fig. (2): Distribution of the lesions in the lungs. 


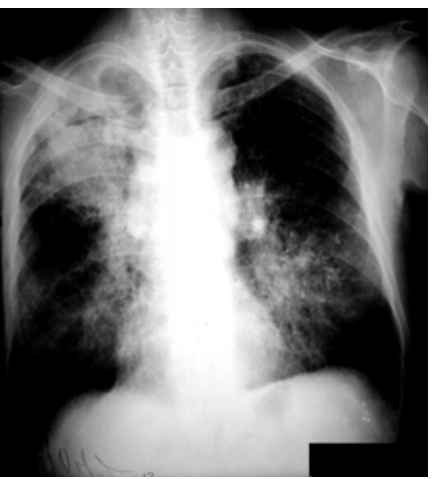

Fig. (3): Shows right peripheral lung lesion $(10 \mathrm{~cm})$.

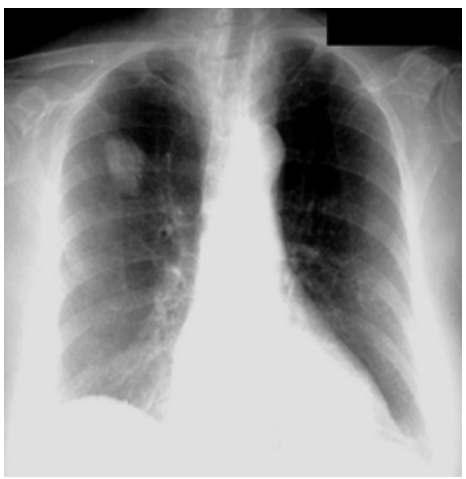

Fig. (4): Shows right apical lung lesion $(3 \mathrm{~cm})$.

Table (1): The sonographic pattern of the 150 lesions

\begin{tabular}{|c|c|c|c|c|c|c|c|}
\hline \multirow{2}{*}{$\begin{array}{l}\text { Types of the } \\
\text { lesions }\end{array}$} & \multirow{2}{*}{$\begin{array}{c}\text { Number of } \\
\text { patients }\end{array}$} & \multicolumn{2}{|c|}{ Hypoechoic lesion } & \multicolumn{2}{|c|}{ Hyperechoic lesion } & \multirow{2}{*}{ Isoechoic } & \multirow{2}{*}{ Mixed } \\
\hline & & Uniform & $\begin{array}{c}\text { Non- } \\
\text { uniform }\end{array}$ & Uniform & $\begin{array}{c}\text { Non- } \\
\text { uniform }\end{array}$ & & \\
\hline Malignant & 140 & $68(48 \%)$ & $24(17 \%)$ & $26(18 \%)$ & $10(7 \%)$ & - & $12(8 \%)$ \\
\hline Tuberculosis & 6 & - & - & - & $2(33 \%)$ & - & $4(66 \%)$ \\
\hline Inflammation & 2 & - & - & - & - & $2(100 \%)$ & - \\
\hline Normal & 2 & - & - & - & - & $2(100 \%)$ & - \\
\hline
\end{tabular}

Table (2): The histological nature of the 140 malignant lesions.

\begin{tabular}{|l|l|l||}
\hline Nature of the lesion & number of cases & Percentage \\
\hline \hline $\begin{array}{l}\text { Adenocarcinoma (include alveolar cell } \\
\text { carcinoma) }\end{array}$ & 52 & $37.1 \%$ \\
\hline Squamous cell carcinoma & 49 & $35 \%$ \\
\hline Small oat cell carcinoma & 11 & $8 \%$ \\
\hline Large cell undifferentiated carcinoma & 11 & $8 \%$ \\
\hline Lymphoma & 5 & $3.4 \%$ \\
\hline Secondary (metastasis) & 11 & $7.8 \%$ \\
\hline Neurofibrosarcoma & 1 & $0.7 \%$ \\
\hline & 140 & $100 \%$ \\
\hline
\end{tabular}




\section{Discussion:}

The clinical features such as patient age, size of the lesions, appearance of the lesions on imaging studies, and patient smoking history help in estimating the probability of malignancy ${ }^{(13)}$. Peripheral thoracic lesions are usually not accessible with fiberoptic bronchoscopic examination and the diagnostic yield of bronchoscopic biopsies is low ${ }^{(14)}$, so in order to reach a final diagnosis in these cases thoracotomy or thoracoscopic biopsies for these peripheral lesions are needed ${ }^{(15,16)}$. Both these investigations will expose the patient to unnecessary surgical procedures. Moreover, most of these patients are not suitable candidates for surgical procedures.

Until recently, ultrasound examination was considered to be of limited utility in the evaluation of chest lesion because the ribs and air in the lungs act as barrier to the ultrasound visualization of the intrapulmonary lesions ${ }^{(17)}$. However, the presence of fluid in the pleural space, tumour, consolidation or atelectasis in the lung provide ample sonographic window for evaluating the intrapulmonary lesions ${ }^{(18)}$. It was proved that ultrasound examination in guiding for lung lesions biopsies has superior advantages on computerized tomography or fluoroscopic guided biopsies. It is an easy and inexpensive examination modality that does not utilize ionizing radiation and can be performed on bed side ${ }^{(18)}$.

In this study the ultrasound guided FNAB was successful in all the 150 patients examined and sufficient amount of lung tissue was gained from the first trial. This makes the diagnostic yield for FNAB to be $100 \%$ compared to $85 \%$ in Khan et al. study and $84 \%$ in both Yang et al and lkezoe et al studies $^{(8,21,24)}$. The cause of this high yield is probably because the diagnosis of malignant pulmonary tumour needs only few cells to make decision.

Fine needle aspirate biopsy is a quick interventional procedure which lasted for only 15 minutes as a mean in our work. It needs no much cooperation of the patients and can succeed even in sick dyspneic patients ${ }^{(19)}$.

In this study we expose every patient to follow up chest X-ray after 4-6 hours to rule out the possibility of developing post FNAB pneumothorax. No single case in this series had developed this complication compared to Yu liao et al. study ${ }^{(20)}$ where $4 \%$ of their cases developed this complication. The factors predisposing to this complication are probably due to preexisting lung diseases, increased lesion's depth and advanced age of the patient. It has no relation to the length of the needle used in FNAB, moreover the needle itself doesn't increase the rate of pneumothorax ${ }^{(21-23)}$.

In our study we came across two cases who had pulmonary lesions in the upper zone of the lung and the histologic result of FNAB revealed normal parenchymal lung tissue. These lesions were isoechoic on ultrasound pattem. Probably the lesion which appears in the chest X-ray was due to pleural thickening while the underlying lung tissue was normal.

\section{Conclusions and recommendations:}

Ultrasound guided transthoracic biopsy with fine needle aspirate appears to be safe and effective method for diagnosing malignant and benign peripheral thoracic lesions especially for those in the lung apex, axilla mediastinal or near the diaphragm where fluoroscopic visualization is difficult. It is quick, safe and efficient method with a high diagnostic yield and can be achieved in critically ill patients. The rate of complications of this procedure is very low and it can help to avoid unnecessary surgical procedures in patients with benign thoracic lesion or an infectious nature or metastatic lung tumours.

We recommend this procedure especially in our developing country where CT scan facilities are few and costly.

\section{References}

1. Dahlgrw SE, Nordenstrom B. Transthoracic needle biopsy. Year book 1966; Chigago.

2. Zelch JV, Lalli AF, Mccormack LJ, Belovicl DM. Aspiration biopsy in the diagnosis of pulmonary nodule. Chest $\mathrm{J}$ 1973; 63:149-152.

3. Sinner WN. Transthoracic needle biopsy of small peripheral malignant lesions. Radiology 1973; 8:305-314.

4. Dick R, Heard BE, Hinson KF, Kew IH and Pearson MC. Aspiration needle biopsy of thoracic lesions. British J. of diseases of the chest 1974; 68: 86-94.

5. Pavy RO, Antic RR, Begley M. Percutaneous aspiration biopsy of discrete lung lesions. Cancer J. 1974; 34:2109-2117.

6. Sargen EN, Turnew AF, Gordonson J, Schwin CP and Pushky O. Percutaneous pulmonary needle biopsy. Am J Radiol, 1974; 122: 758768.

7. Floww CDR, Verncy GI. Percutaneous needle biopsy of thoracic lesions. An evaluation of 300 Biopsies. Clinical Radiology 1979; 30:215-218.

8. Khan GQ, Tanvir M. Iftikhar M. Fine needle biopsy of peripheral pulmonary 
lesions under real-time sonographic guidance JIMA 1998; 30:5-8.

9. Westcott JL. Direct percutaneous needle aspiration of localized pulmonary lesions. Result of 422 patients. Radiology 1980; 137:31-35.

10. Khori NF, Stitire FP, Erozan YS, Transthoracic needle aspiration biopsy of benign and malignant lung lesions Am. J Radiol 1985; 144:281-288.

11. Westcott JL. Percutaneous transthoracic needle biopsy. Radiology 1998; 169:593-601.

12. Sheth S, Hampw UM, Stanley DB, Wheeler JH, Smith DA. US guidance for thoracic biopsy "a valuable alterative to CT. Radiology 1999; 210:721-728.

13. Cummings SR, Lillington GA, Richard RJ. Estimating the probability of malignancy in solitary pulmonary nodules. Am Rev. Respir disease. 1986; 34: 449-450.

14. Mark JBD, Marglin SJ, Castellino RA. The role of bronchoscopy and needle aspiration in diagnosis of peripheral lung mass J. thoracic cardiovasc. Surg. 1998; 76: 266-268.

15. Mack MJ, Hazelringg SR, Landreneau RJ, Acuff TE. Thoracoscopy for the diagnosis of the indeterminate solitary pulmonary nodules. Ann thoracic surgery. 1993; 56: 825-832.

16. Mitrukas, Landreneau RJ. Diagnosting the indeterminate pulmonary nodule percutaneous biopsy versus thoracoscopy. Surgery 1995; 118:676684.
17. Izumi S, Tamaki S, Natori $H$. Ultrasonically guided aspiration needle biopsy in diseases of the chest. Am. Rev Respir Dis. 1982; 125: 460-462.

18. Yu CJ, Tang PC, Wuhd, Chang DB. Ultrasound study in unilateral hemithorax opacification. Rev Resp. Dis. 1993; 174: 430-440.

19. Ruben DJ, Strang JG, Fultz PJ, Gottlieb $\mathrm{RH}$. Sonographic guidance of mediastinal biopsy. An effective alternative to CT guidance. Am J Radiol 1997; 169: 1605-1610.

20. Wei-Yu Liao, Ming-Zen Chen, YihLeong Chang. Ultrasound guided transthoracic cutting biopsy for peripheral thoracic lesions. Less than 3cm. Radiolgy. 2000; 217:685-691.

21. Yang PC, Chang DB, Yu CJ. Ultrasound guided core biopsy of thoracic tumours. Am Rev. Respir Dis. 1992; 146:763-767.

22. Arakawa $H$, Nakajima, Kurihara $Y$. CT guided transthoracic needle biopsy comparison between automated biopsy gun and fine needle aspiration, Clinical Radiol. 1996; 5:503-506.

23. Hayashi N, Sakai T, Kitagawa. CT guided biopsy for pulmonary nodules less than $3 \mathrm{~cm}$ usefulness of the spring operated core biopsy needle and Frozen section pathological diagnosis. Am. J. Roentegnol 1998; 170:329-333.

24. Ikezoe J, Sone S, Higashihara T. Sonography guided aspiration biopsy for diagnosis of thoracic lesions. Radiology 1984; 143: 229-234. 